\title{
Halogen Bonding and $\pi \ldots \pi$ Stacking Control Reactivity in the Solid State
}

Tullio Caronna, ${ }^{\circ}$ Rosalba Liantonio, $†$ Thomas A. Logothetis, $†$ Pierangelo Metrangolo, ${ }^{\star}, \dagger$ Tullio Pilatił, and Giuseppe Resnati ${ }^{\star} \dagger$

${ }^{\dagger}$ Department of Chemistry, Materials, and Chemical Engineering “G. Natta”, Polytechnic of Milan

Via Mancinelli 7, Milan (I), ${ }^{\ddagger}$ CNR-I.S.T.M., University of Milan, Via Golgi 19, Milan (I), and

'University of Bergamo, Faculty of Engineering, Via Marconi 5, 24044 Dalmine, Bergamo (I)

\section{Supporting Information}

General: Commercial HPLC-grade solvents were used without further purification. Starting materials were purchased from Sigma-Aldrich, Acros Organics, and Apollo Scientific, and used without further purification. Reactions were carried out in oven dried glassware under a nitrogen atmosphere. NMR spectra were recorded at room temperature with Bruker AC 250 and AV 500 spectrometers. For ${ }^{1} \mathrm{H}$ $\mathrm{NMR}$ and ${ }^{13} \mathrm{C}$ NMR spectra, $\mathrm{CDCl}_{3}$ was used as both solvent and internal standard. ${ }^{19} \mathrm{~F}$ NMR (235 $\mathrm{MHz}$ ) spectra were recorded in $\mathrm{CDCl}_{3}$ with $\mathrm{CFCl}_{3}$ as internal standard. All chemical shift values are stated in ppm. 2,2,2-Trifluoroethylether was used as internal standard to determine the ${ }^{19} \mathrm{~F} /{ }^{1} \mathrm{H}$-ratio, where applicable. The NMR spectra of the co-crystals were integrated so that in the ${ }^{1} \mathrm{H}$ NMR spectrum the $\mathrm{CH}_{2} \mathrm{O}$ quartet of the 2,2,2-trifluoroethylether was corresponding to four and in the ${ }^{19} \mathrm{~F}$ NMR spectrum the $\mathrm{CF}_{3}$ of the 2,2,2-trifluoroethylether was corresponding to six; by this procedure the ${ }^{19} \mathrm{~F} /{ }^{1} \mathrm{H}-$ ratio of each co-crystal was determined. IR spectra (KBr pellets) were obtained using in a Perkin-Elmer 2000 FT-IR spectrometer, and the values are in $\mathrm{cm}^{-1}$. Mass spectra were recorded with a Finnigan Mod TSQ-70 instrument in FAB mode from a m-NBA matrix. The X-ray crystal structures were determined using a Bruker Smart Apex diffractometer. Melting points were established with a Reichert instrument by observing the melting and crystallising process in a microscope using polarised light. The photoreaction was carried out in a Rayonet RPR-100 instrument using monochromatic irradiation at $\lambda=$ $300 \mathrm{~nm}$.

General Procedure for the Synthesis of Co-crystal 5a,b: Co-crystallisations were carried out following the liquid-liquid diffusion technique. An nearly saturated solution of $\mathbf{3}$ in chloroform and a nearly saturated solution of base 4 (2 equivalents) in the same solvent were mixed in a clear borosilicate vial. The opened vial was placed in a closed cylindrical wide-mouth bottle containing carbon 
tetrachloride and solvents were allowed to diffuse at room temperature until crystals were formed. The crystals 5 were filtered off the mother liquor, washed with pentane and rapidly dried in air at room temperature.

\section{Synthesis of pentaerythritol tetrakis(2,3,5,6-tetrafluoro-4-iodophenyl) ether (3).}

Finely powdered solids pentaerythritol 1 (1.00 eq, $20.2 \mathrm{mmol}, 2.75 \mathrm{~g}$ ) and cesium carbonate (5.00 eq, $101 \mathrm{mmol}, 32.9 \mathrm{~g}$ ) were suspended in pentafluoroiodobenzene (2) (10.0 eq, $202 \mathrm{mmol}, 26.9 \mathrm{ml})$ and vigorously stirred while the mixture is heated to $150{ }^{\circ} \mathrm{C}$ for approximately 5 hours. The reaction is monitored by TLC on silica gel plates $\left(\mathrm{R}_{\mathrm{f}}=0.42\right.$, EtOAc: $n$-hexane 1:5). The resulting suspension was partitioned between diethyl ether and brine, the aqueous phase extracted twice with chloroform. The combined organic phases were washed with brine and dried over sodium sulfate. Flash chromatography of the dry crude mixture with toluene:chloroform: $n$-hexane 1:2:13 $\left(\mathrm{R}_{\mathrm{f}}=0.39\right)$ affords a clean product, which was purified by crystallisation from dichloromethane/n-heptane to yield off-white crystalline ether 3 (4.74 g, 20 \%). M.p. $=439 \mathrm{~K} ;{ }^{1} \mathrm{H}-\mathrm{NMR}$ : $\delta=4.61$ (s, 8H, $\left.\mathrm{CH}_{2}\right) ;{ }^{13} \mathrm{C}-\left\{{ }^{1} \mathrm{H}\right\}$-NMR: $\delta=47.62$ (s, C), $65.28\left(\mathrm{t},{ }^{2} J_{\mathrm{CF}}=27 \mathrm{~Hz}, C-\mathrm{I}\right), 71.67\left(\mathrm{~s}, C_{2}\right), 137.70(\mathrm{~m}, C-\mathrm{O}), 140.63\left(\mathrm{dm}_{\mathrm{c}},{ }^{1} J_{\mathrm{CF}}=251 \mathrm{~Hz}\right.$, ortho-C), $147.48\left(\mathrm{dm}_{\mathrm{c}},{ }^{1} J_{\mathrm{CF}}=242 \mathrm{~Hz}\right.$, meta-C); ${ }^{19} \mathrm{~F}-\mathrm{NMR}: \delta=-154.96\left(\mathrm{~d},{ }^{3} J_{\mathrm{FF}}=16 \mathrm{~Hz}, 8 \mathrm{~F}, \mathrm{OCCF}\right),-120.92(\mathrm{~d}$, $\left.{ }^{3} J_{\mathrm{FF}}=16 \mathrm{~Hz}, 8 \mathrm{~F}, \mathrm{ICCF}\right) . \mathrm{IR}: v_{\max }=2968,1633,1490,1470,1452,1393,1309,1277,1165,1103,991$, 967, 943, $804 \mathrm{~cm}^{-1}$. MS (FAB in $\left.\mathrm{mNBA}\right): 1232(40)\left\{\mathrm{M}^{+*}\right\}$.

\section{Co-crystal $5 a$.}

1,2-Diaminoethane (4a) $(79.5 \mu \mathrm{mol}, 5.32 \mu \mathrm{l})$ and $\mathbf{3}$ (39.8 $\mu \mathrm{mol}, 49.0 \mathrm{mg})$ were co-crystallised to afford crystalline 5a (m.p. $435 \mathrm{~K}$ ) in an acceptor/donor ratio of 1:2. ${ }^{1} \mathrm{H}-\mathrm{NMR}: \delta=2.75$ (s, 8H, $\mathrm{NCH}_{2}$ ), 4.62 (s, 8H, OCH ) $^{19}{ }^{19}$ F-NMR: $\delta=-155.02$ (m, 8F, 2-,6-F), -121.20 (m, 8F, 3-,5-F). IR: $v_{\max }=2964,1631$, $1591,1490,1094,983,807 \mathrm{~cm}^{-1}$.

\section{Co-crystal $5 b$.}

Trans-1,2-bis(4-pyridyl)ethene (4b) (2.00 eq, $95.8 \mu \mathrm{mol}, 17.5 \mathrm{mg})$ and 3 (47.9 $\mu \mathrm{mol}, 59.0 \mathrm{mg})$ were cocrystallized to afford crystalline $5 \mathbf{b}$ (m.p. $494 \mathrm{~K}$ ) in an acceptor/donor ratio of 1:2. ${ }^{1} \mathrm{H}-\mathrm{NMR}$ : $\delta=4.61$ (s, $\left.\mathrm{CH}_{2}, 8 \mathrm{H}\right), 7.22(\mathrm{~s}, 4 \mathrm{H}, \mathrm{CH}), 7.40\left(\mathrm{~d},{ }^{3} \mathrm{~J}_{\mathrm{HH}}=6 \mathrm{~Hz}, 8 \mathrm{H}, \mathrm{CH}=\mathrm{CH}-\mathrm{N}\right), 8.64\left(\mathrm{~d},{ }^{3} \mathrm{~J}_{\mathrm{HH}}=6 \mathrm{~Hz}, 8 \mathrm{H}, \mathrm{CH}=\mathrm{CH}-\right.$ 
N). ${ }^{19}$ F-NMR: $\delta=-154.96$ (m, 8F, 2-,6-F), -120.98 (m, 8F, 3-,5-F). IR: $v_{\max }=3034,2966,2875,1630$, 1598, 1101, 994, 967, 957, 819, 796, $543 \mathrm{~cm}^{-1}$.

Photodimerization of co-crystal $5 b$ and subsequent isolation of $r-1, c-2, t-3, t-4-t e t r a-(4-p y r i d y l)-$ cyclobutane (6).

Co-crystal 5b (62.6 $\mu \mathrm{mol}, 100 \mathrm{mg})$ was finely powdered and spread as a thin layer between two quartzglass plates, and then it was irradiated for three hours at $\lambda=300 \mathrm{~nm}$ under TLC control (EtOAc/MeOH, 7:3, $\mathrm{R}_{\mathrm{f}}$ values: 3: 0.78, 4b: 0.35, 5b: 0.1). The resulting yellow solid (100 $\mathrm{mg}, 100 \%$ ) was analysed by NMR and FT-IR. Isolation was achieved either by flash-chromatography (using the solvents mentioned for TLC with a gradient from 7:3 to 1:1) or by partition of protonated 6 (diluted hydrochloride acid) and 3 between water and chloroform with subsequent extraction of deprotonated (soda solution) 6 into chloroform. Both methods allow for the recovery of the template $\mathbf{3}$ which can be used for further cocrystallisation without loss of activity. M.p. $=507 \mathrm{~K}(\mathbf{6}) .{ }^{1} \mathrm{H}-\mathrm{NMR}: \delta=4.47(\mathrm{~s}, 4 \mathrm{H}, \mathrm{CH}), 6.99\left(\mathrm{~d},{ }^{3} J_{\mathrm{HH}}=\right.$ $6 \mathrm{~Hz}, 8 \mathrm{H}, \mathrm{CH}=\mathrm{CH}-\mathrm{N}), 8.44\left(\mathrm{~d},{ }^{3} J_{\mathrm{HH}}=6 \mathrm{~Hz}, 8 \mathrm{H}, \mathrm{CH}=\mathrm{CH}-\mathrm{N}\right)$. MS (FAB in $\left.m \mathrm{NBA}\right): 429(40)\left\{\mathrm{M}^{+*}\right\}$. 
Figure 3. The exclusive formation of the rctt isomer is observed. This implies that whenever the reaction occurs, the arrangement of the olefins is as described in green.

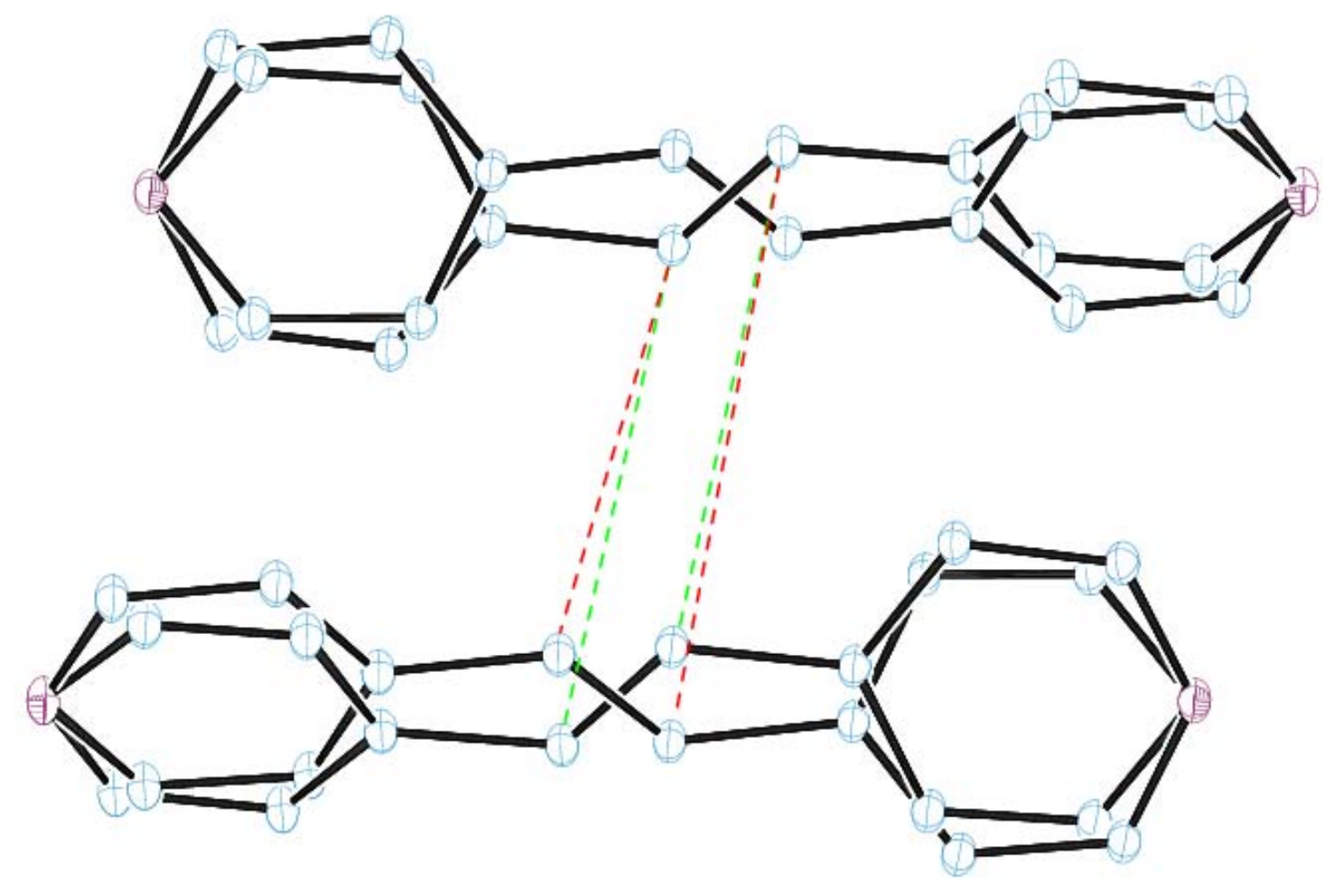

